\title{
CRÉDITO PRESUMIDO DO IPI E INSUMOS NÃO TRIBUTADOS PELO PIS/PASEP E PELA COFINS: MATO OU MORRO!
}

\section{José Roberto Vieira}

Mestre e Doutor em Direito do Estado - Direito Tributário da PUC/SP, Professor de Direito Tributário da UFPR e da Faculdade de Direito das Faculdades Integradas Curitiba e Estudos Pós-Graduados no Instituto de Estudios Fiscales, Espanha, Auditor da Receita Federal, Membro do Conselho de Contribuintes do Ministério da Fazenda.

\begin{abstract}
SUMÁRIO: Introdução: Mato ou Morro; 1 Perfil Legal do Incentivo; 2 Aquisição de Insumos não Tributados pelo PIS/PASEP e pela COFINS; 3 Interpretação Teleológica; 4 Interpretação Histórico-Evolutiva; 5 Interpretação Literal; 6 Não Interpretação Liberal, mas Sistemática; 7 Não as Instruções Normativas, mas a Lei; Conclusão: Mato ou Morro.

"A linguagem é um deus ciumento que não tolera que suas palavras sejam tomadas em vão, lançando o pecador na confusão e na obscuridade." (KARL POPPER) ${ }^{1}$
\end{abstract}

\section{INTRODUÇÃO: MATO OU MORRO}

Estamos numa biblioteca, este lugar que já foi comparado com um enorme cemitério, mas encantado, com uma necrópole colossal, porém mágica. Magia e encantamento devidos à miraculosa faculdade que temos de fazer com que aqui os mortos ressuscitem, acordem de seu sono e, pela graça de suas milhares de vidas, experiências e reflexões, façam-nos igualmente acordar, e mesmo até muitas vezes ressuscitar! Tudo pelo uso adequado desse instrumento de maravilhas, ao qual já dedicamos boa parte de nossa vida: o livro! ${ }^{2}$

1 Conjecturas e refutações: o progresso do conhecimento científico. Trad. de Sérgio Bath. Brasília: Universidade de Brasília, 1980, p. 45.

2 Embora objeto privilegiado de nossas preocupações, cabe, de passagem, registrar que, depois da sua utilização, mais do que cuidadosa, carinhosa, é conveniente devolver o livro, com todo o respeito e a gratidão que ele merece, ao seu lugar na prateleira; e deixar a biblioteca rumo à vida. Conquanto de valor incalculável e quase sempre inalcançável, o livro cede passo, na vida, a bens ainda mais valiosos. E invocamos o testemunho insuspeito de NORBERTO BOBBIO, em suas memórias: “... continuo aqui ... sentado diante da escrivaninha de meu grande escritório, com suas quatro paredes forradas de livros, cada vez mais inúteis ... Hoje alcancei a tranqüila consciência ... de ter chegado apenas aos pés da árvore do conhecimento. Não foi do meu trabalho que obtive as alegrias mais duradouras de minha vida ... Obtive-as dos meus relacionamentos, dos mestres que me educaram, das pessoas que amei e que me amaram". Consciência que só o tempo, com o auxílio dos livros, nos proporciona: "O mundo do velho ... é um mundo onde contam mais os afetos que os conceitos" - O tempo da memória: de Senectute e outros escritos autobiográficos. Trad. de Daniela Versiani. Rio de Janeiro: Campus, 1997, 
Hoje, contudo, esse jardim de delícias impressas está a frustrar-nos. Vasculhamos e reviramos muitos dos seus dez mil exemplares, e nada! Bem sabemos qual o texto a ser localizado, e que ele aqui se encontra, mas, sejamos honestos, ignoramos-lhe o autor e a obra. O mais próximo que chegamos foi a alguns excertos do livro $O$ Gato do Mato e o Cachorro do Morro, de ANA MARIA MACHADO, esse expoente da literatura infantil nacional, entre os quais, no entanto, não deparamos o bendito (ou maldito) texto. ${ }^{3}$

E começamos a entender a indagação aflita de FERNANDO SAVATER, o filósofo espanhol contemporâneo, acerca da nossa memória: "No vivimos ... amenazados por ella como por la inexorable Moira ?". ${ }^{4}$ Entretanto, conforta-nos o fato de que essa implacável deusa do destino exerceu esses mesmos angustiantes poderes para atormentar a vida de outros tantos, entre os quais grandes nomes e conhecedores de nossa literatura. Recordo-me vivamente, por exemplo, da narrativa emocionada de ÉRICO VERÍSSIMO, esse soberbo literato que dividiu as nossas letras do século XX com JORGE AMADO, relatando sua escalada da colina da Acrópole num entardecer grego, referindo o olhar então lançado para Atenas, e especialmente contando o seu postar-se comovido diante do Partenon: "Foi aqui que, por assim dizer, começou a chamada Civilização Ocidental. Alguém - quem foi mesmo, ó memória? - disse que ...". 5

E o consolo da universalidade desses poderes ilimitados de Moira, a tecelã de nossos destinos, que neste momento nos frustra, vem acompanhado da esperança da anistia. Afinal, é outra vez SAVATER quem nos lembra que os nossos são tempos de ansiedade desmedida por memórias, confidências, desabafos e intimidades, cuja paga indulgente é a mecânica e habitual remissão: "Vivimos una época en la que ... todo el que confiesa queda automáticamente absuelto ...". ${ }^{6}$

Rezado o Confiteor, e esperançoso da clemência dos leitores, passemos enfim à estória, pois a ausência de sua origem ou autoria não a torna menos adequada ao tema que aqui desenvolveremos nem menos saborosa.

Conta-se que um turista, viajando por um país em processo de revolução, encontrava-se em uma pequena cidade do seu interior, quando, certa noite, em meio ao seu costumeiro passeio noturno, deparou-se com um salão comunitário repleto de moradores da localidade, ao qual curiosamente adentrou. Usava da palavra um líder

3 LAJOLO, Marisa (org.). Ana Maria Machado: seleção de textos ... Literatura comentada. São Paulo: Abril, 1983, p. 66-68.

4 Corazón de la Memoria. In: A Decir Verdad. Madrid: Fondo de Cultura Económica, 1987, p. 311. Para os antigos gregos, Moira (mais tarde transformada nas três Moiras ou Parcas), embora não integrando o grupo seleto dos deuses que habitavam o Olimpo, era a deusa do destino (MURRAY, Alexander S. Quién es quien en la mitología. Trad. de Cristina María Borrego. 2. ed. Madrid: EDIMAT, 2000, p. 199-200), metaforicamente representada por uma tecelã, porque se acreditava que cabia aos deuses a faculdade de tecer o destino dos homens (BORGES, José Souto Maior. Entre o Destino e a Vontade. In: Ciência Feliz. 2. ed. São Paulo: Max Limonad, 2000, p. 85).

5 Sol e Mel. In: Solo de Clarineta: memórias. Porto Alegre: Globo, v. 2, 1975, p. 41-42.

6 Pleamar de la Memoria. In: Instrucciones para Olvidar El Quijote. Madrid: Taurus, 1996, p. 107. 
revolucionário que, naquele preciso instante, dizia ao povo atento: "Agora é mato ou morro!". E imediatamente o turista encheu-se de admiração pela coragem e ousadia tanto daquele líder quanto da audiência, que apresentava sinais explícitos de assentimento e concordância; e instantaneamente apreciou, pasmo, o poder extraordinário de uma ideologia política cujo evidente apoio popular, provavelmente fruto da opressão dos donos do poder, permitia àquele líder propor, com nitidamente boa receptividade, o recurso extremo de levar os ideais revolucionários às últimas conseqüências, assumindo o risco supremo de a eles dedicar a vida ou a morte própria ou alheia!

Ledo engano, ou ledo e ivo engano, como preferiria dizer CARLOS HEITOR CONY.7 Tivesse o turista ingressado no recinto um momento antes e não se teria limitado a escutar apenas a sentença - “... mato ou morro!” - com toda a sua fatal ambigüidade, não tendo sido induzido às elucubrações especulativas, filosófico-políticas e idealistas a que se entregou. Tivesse o visitante chegado à sala pouco mais cedo e teria percebido com clareza o ambiente que cercava e antecedia aquela afirmativa, influenciado pelo arrependimento e pela lástima, de que participavam líder e povo, reconhecendo todos com pesar e remorso a precipitação infeliz e desastrosa do movimento revolucionário, então prestes a sucumbir. Tivesse ele um mínimo de calma e tranqüilidade, e teria aguardado um momento mais, para entender o clima que sucedia àquela assertiva, imbuído da certeza triste e desgostosa da necessidade premente de enfrentar uma temida e provavelmente violenta reação governamental. Tivesse esse intérprete apressado e impaciente pequena dose de prudência e cautela e, mais do que o texto, teria apreendido o contexto, em que "mato" e "morro" não eram verbos conjugados no presente do indicativo, mas substantivos concretos, comuns, no exercício da função sintática de adjuntos adverbiais de lugar, indicando direção e destino. Em outras palavras, quando o líder revolucionário dizia “Agora é mato ou morro!", não estava incitando a ação do povo na luta até às últimas instâncias, mas, muito pelo contrário, estava a aconselhá-lo e estimulá-lo à fuga imediata e desenfreada, dizendo-o diante de uma única e exclusiva alternativa: "Agora é ... fugir para o mato ou fugir para o morro!".

Essa valorização descomunal do texto, atitude interpretativa de miserável estreiteza, implica a desvalorização sem medida da interpretação pelo contexto, este procedimento hermenêutico de fecunda amplitude. Em casos como o dessa espirituosa estória, inocente e inconseqüente, sem maiores prejuízos. Em casos como o do crédito presumido do IPI nas aquisições de insumos não tributados pela Contribuição ao PIS ou pela COFINS, como em seguida demonstraremos, não só com danos consideráveis aos exportadores nacionais, mas também ao espírito da Lei concessiva do incentivo, $e$ sobretudo à própria Legalidade Tributária, como superior princípio constitucional.

7 Jogo de palavras para aludir a LÊDO IVO, o poeta, romancista e ensaísta alagoano, membro da Academia Brasileira de Letras, e integrante da chamada "geração de 1945", que ofereceu alternativas e alguns contrapontos às idéias e tendências do primeiro modernismo. BOSI, Alfredo. História concisa da literatura brasileira. São Paulo: Cultrix, 1970, p. 517; e FERNANDES, Rinaldo de. Notas biobibliográficas. In: JOSÉ NÊUMANNE PINTO, Os cem melhores poetas brasileiros do século. São Paulo: Geração, 2001, p. 144. 


\section{PERFIL LEGAL DO INCENTIVO}

Culminando uma longa seqüência de 27 (vinte e sete) medidas provisórias, iniciada com a de $n^{\circ} 674$, de 25.10.1994, e terminada com a de $n^{\circ} 1.484-27$, de 22.11.1996, finalmente convertida na $\operatorname{Lei~}^{\circ}$ 9.363, de 13.12.1996, este diploma legal instituiu o "... crédito presumido do Imposto sobre Produtos Industrializados ...", concedido à “... empresa produtora e exportadora de mercadorias nacionais ...", como ressarcimento das contribuições PIS/PASEP e COFINS, “... incidentes sobre as respectivas aquisições, no mercado interno, de matérias-primas, produtos intermediários e material de embalagem, para utilização no processo produtivo" (art. $1^{\circ}$, caput); elegendo como base de cálculo do crédito presumido o valor obtido "... mediante a aplicação, sobre o valor total das aquisições de matérias-primas, produtos intermediários e material de embalagem ... do percentual correspondente à relação entre a receita de exportação e a receita operacional bruta do produtor exportador" (art. $2^{\circ}$, caput); base de cálculo essa sobre a qual se promove a "... aplicação do percentual de $5,37 \%$..." (art. $2^{\circ}, \S 1^{\circ}$ ), para afinal encontrar o valor do crédito presumido.

Tal crédito, um visível e manifesto estímulo aos estabelecimentos industriais que destinam seus produtos industrializados à exportação, pode ser por eles utilizado na conta corrente do IPI, como uma dedução do imposto devido. Entretanto, na condição de um incentivo tributário, de que desfruta, o crédito presumido dispõe de outras alternativas de utilização, tal como a transferência para outros estabelecimentos da mesma empresa $\left(\operatorname{art} .2^{\circ}, \S 3^{\circ}\right.$ ) e inclusive o ressarcimento em moeda corrente (art. $6^{\circ}$ ), na forma estabelecida pelos atos administrativos normativos pertinentes.

\section{AQUISIÇÃO DE INSUMOS NÃO TRIBUTADOS PELO PIS/PASEP E PELA COFINS}

Tratando-se de um crédito outorgado aos produtores-exportadores "... como ressarcimento das contribuições ..." - PIS/PASEP e COFINS - “... incidentes sobre as respectivas aquisições, no mercado interno, de matérias-primas, produtos intermediários e material de embalagem, para utilização no processo produtivo" (art. $1^{\circ}$ ); não serão poucos os que partirão da literalidade do texto legal concessivo do benefício para deduzir como cabivel o ressarcimento das contribuições apenas e tão-somente quando tiver havido a sua incidencia. De modo que, inexistindo PIS/PASEP ou COFINS numa específica aquisição de insumos, nada haveria a ser ressarcido, por esse caminho interpretativo, descabendo o crédito presumido.

Esse foi o entendimento assumido pela administração tributária federal, ao expedir a Instrução Normativa $S R F n^{\circ} 23$, de 13.03.1997, cujo art. $2^{\circ}$, $\S 2^{\circ}$, estabeleceu: "O crédito presumido relativo a produtos oriundos da atividade rural ... utilizados como matéria-prima, produto intermediário ou embalagem, na produção de bens exportados, será calculado, exclusivamente, em relação às aquisições, efetuadas de pessoas jurídicas, sujeitas às contribuições PIS/PASEP e COFINS". Entendimento mantido na Instrução Normativa SRF $n^{\circ} 103$, de 30.12.1997, quando determinou, em seu art. $2^{\circ}$, que "as matérias-primas, produtos intermediários e materiais de embalagem adquiridos de 
cooperativas de produtores não geram direito ao crédito presumido"; e ainda hoje prevalecente, como demonstra a orientação constante da resposta à pergunta $\mathrm{n}^{\circ} 728 \mathrm{da}$ obra "Perguntas e Respostas 2002", editada pela Secretaria da Receita Federal: "No caso de o insumo ser fornecido por pessoa jurídica não sujeita ao PIS/PASEP e COFINS, ou diretamente por pessoa física, não há direito ao crédito presumido destes insumos (ainda que em etapas anteriores tenha havido incidência das contribuições)"; orientação essa confirmada pela resposta à pergunta $\mathrm{n}^{\circ} 723$ da mesma obra, que, tratando das aquisições de cooperativas, tal como as de pessoas físicas, não sujeitas àquelas contribuições, afirma a sua exclusão do cálculo do crédito presumido. ${ }^{8}$

Dentre tantas outras questões atinentes ao crédito presumido, essa tem sido objeto de numerosos processos administrativos tributários e de freqüente e acirrada discussão nos tribunais administrativos (Conselhos de Contribuintes e Câmara Superior de Recursos Fiscais). E muito embora venham preponderando as decisões contrárias à referida orientação administrativa, existem também acórdãos que a prestigiam, além de bom número de votos divergentes com argumentos nem sempre desprezíveis. Lamentavelmente, a boa doutrina não tem dedicado ao tema a atenção que ele merece, com raras e honrosas exceções. ${ }^{9}$

Este trabalho tem a pretensão (intenção), despida de pretensão (presunção), de responder razoavelmente a essa carência doutrinária, demonstrando que a orientação administrativa vigente constitui apego à letra dos atos administrativos normativos indicados ou apego à letra de um único dispositivo legal (Lei $\mathrm{n}^{\circ} 9.363 / 96$, art. $1^{\circ}$, caput), apartado do contexto das normas legais em que ele se insere.

\section{INTERPRETAÇÃO TELEOLÓGICA}

Numa preocupação inicial com a finalidade da norma do crédito presumido, principie-se por indagar se, na época da criação do incentivo, quando ambas as contribuições apresentavam a incidência somada de $2,65 \%$ (0,65\% de PIS e $2 \%$ de COFINS), por que razão o crédito presumido, que, segundo a administração tributária, visaria exclusivamente ao ressarcimento dessas contribuições incidentes na operação de aquisição, seria calculado pela aplicação do percentual de 5,37\% (pouco mais que o dobro) sobre a base de cálculo definida na lei? Por que ressarcir por um percentual de $5,37 \%$ contribuições que incidiram na operação anterior com uma alíquota conjunta de $2,65 \%$ ?

8 Ministério da Fazenda - Secretaria da Receita Federal, 2002, p. 407-408 e 405.

9 Entre essas exceções, destacamos, por justiça, um belo trabalho de RICARDO MARIZ DE OLIVEIRA, conhecido advogado e especialista em Direito Tributário: Crédito Presumido de IPI para Ressarcimento de PIS e COFINS - Direito ao Cálculo sobre Aquisições de Insumos não Tributadas, Tributo. Revista do Instituto Cearense de Estudos Tributários - ICET, Fortaleza, ICET e ABC, n. 2, p. 271-311, jan.jul. 2001. 
Encontraremos um princípio de resposta na Exposição de Motivos que justificou a Medida Provisória ${ }^{\circ}$ 948, de 23.03.1995, uma daquelas que antecedeu à Lei ${ }^{\circ}$ 9.363/ 96: "Sendo as contribuições da COFINS e PIS/PASEP incidentes em cascata, sobre todas as etapas do processo produtivo, parece mais razoável que a desoneração corresponda não apenas à última etapa do processo produtivo, mas sim às duas etapas antecedentes, o que revela que a alíquota a ser aplicada deve ser elevada para 5,37\% ...". ${ }^{10}$ Ou seja, o legislador está aqui a reconhecer expressamente que, em face da cumulatividade dessas contribuições, devem ser levadas em conta "... as duas etapas antecedentes ..." (as duas últimas operações), e não apenas a operação de aquisição (a última operação), como quer a óptica da administração tributária.

Aí está o motivo claro da escolha do percentual de 5,37\%, que não só considera uma dupla incidência dessas contribuições $(2,65 \%+2,65 \%=5,30 \%)$, mas também leva em conta que, numa segunda operação tributável, os valores das contribuições incidentes na operação anterior entrariam na base de cálculo das mesmas $(2,65$ x 2,65\% $=0,07)$; donde o percentual de 5,37\% $(5,30 \%+0,07 \%=5,37 \%)$.

Não se diga que, ao buscarmos a mencionada exposição de motivos, estaríamos perseguindo a vontade do legislador. É, aliás, do que cogita JORGE FREIRE, em interessante declaração de voto, em julgamento do Conselho de Contribuintes. ${ }^{11}$ Essa forma de interpretação, identificada não só como “... um terreno movediço", mas também como “... teoria decrépita” por CARLOS MAXIMILIANO, o grande teórico nacional da interpretação jurídica, deve jazer hoje sepultada, porque, obviamente, "com a promulgação, a lei adquire vida própria ...", inexistindo cordão umbilical que a mantenha conectada ao legislador; e porque, afinal, “... a lei não é o que o legislador quis, nem o que pretendeu exprimir, e, sim, o que exprimiu de fato". ${ }^{12}$ No mesmo sentido, o raciocínio apurado de FRANCESCO FERRARA, o antigo professor italiano da Universidade de Pisa. ${ }^{13}$ Estamos, isso sim, em busca da vontade da lei, no encalço de uma explicação plausível para um crédito presumido que funciona como ressarcimento de contribuições que incidiam em cada operação com a alíquota conjunta de $2,65 \%$, e que é calculado com a alíquota de 5,37\%! Em flagrante descompasso, pois, com a idéia de ressarcimento das contribuições incidentes na específica operação de aquisição, como deseja a administração tributária federal!

E tanto é verdade que estamos a diligenciar no sentido da voluntas legis e não no da voluntas legislatoris, que, uma vez afastada a primeira alternativa, indicando $\mathrm{um}$

10 Apud OSWALDO TANCREDO DE OLIVEIRA, Voto do Conselheiro-Relator, Acórdão n 202-09.744, de 09.12.1997, $2^{\circ}$ Conselho de Contribuintes, $2^{\text {a }}$ Câmara, inédito, p. 9.

11 Declaração de Voto, Acórdão n ${ }^{\circ}$ 201-72.668, de 27.04.1999, $2^{\circ}$ Conselho de Contribuintes, $1^{\text {a }}$ Câmara, inédito, p. 19: "Não há que se perquirir da intenção do legislador, mormente analisando a exposição de motivos de determinada norma jurídica que institui benefício fiscal ...".

12 Hermenêutica e aplicação do direito. 11. ed. Rio de Janeiro: Forense, 1991, p. 29, 22, 30 e 31.

13 Interpretação e aplicação das leis. Trad. de Manuel A. Domingues de Andrade. 4. ed. Coimbra: Arménio Amado, 1987, p. 134. 
ressarcimento muito específico das contribuições incidentes na última operação de aquisição, como apetecia ao fisco federal, a partir da justificativa do legislador e do percentual eleito para o cálculo do incentivo, empreendemos agora novo passo, à luz do mesmo dispositivo que é invocado pelos partidários da interpretação literal que exige a incidência na última operação de aquisição (Lei $\mathrm{n}^{\circ} 9.363 / 96$, art. $1^{\circ}$, caput). Sua redação - “... crédito presumido ... como ressarcimento das contribuições ... incidentes sobre as respectivas aquisições ..." de insumos - tanto pode conduzir na direção de uma segunda alternativa, apontando para um ressarcimento menos específico das contribuições incidentes nas duas últimas operações de aquisição, como declarou pretender o legislador, como também pode encaminhar no rumo perfeitamente possível de uma terceira alternativa, aludindo a um ressarcimento mais genérico das contribuições incidentes nas aquisições de insumos, independentemente do número de operações. E embora a intenção do legislador seja conhecida, pois manifesta na indigitada exposição de motivos, ficaremos com esta última inteligência legal, pois é indubitavelmente a que melhor corresponde à intenção da lei, conjugados o dispositivo analisado com a sistemática de cálculo do incentivo (art. $2^{\circ}$ ).

Confira-se o raciocínio de RICARDO MARIZ DE OLIVEIRA, no caso, cogitando da norma do art. $1^{\circ}$ e da "... sua consideração em conjunto com os demais dispositivos dessa mesma lei, especialmente com os que estatuem a fórmula de cálculo do crédito presumido ...", para concluir: “... verifica-se que a alusão ao ressarcimento das contribuições incidentes somente pode ser referida a todas as incidências que possivelmente tenham ocorrido em qualquer anterior etapa do ciclo econômico do produto exportado e dos seus insumos". ${ }^{14}$ Confluente a ponderação de OSWALDO TANCREDO DE OLIVEIRA, ex-membro julgador do Conselho de Contribuintes: “... se não devessem ser levadas em consideração as fases anteriores da comercialização dos produtos para se apurar o valor das contribuições que oneram o custo das mercadorias exportadas ... então desnecessário seria a elaboração de cálculos para se chegar a uma média presumida das onerações das etapas anteriores, conforme procederam as autoridades competentes da área econômica" (sic). ${ }^{15} \mathrm{Na}$ verdade, o legislador, considerando as possíveis incidências das etapas anteriores, em virtude da cumulatividade do PIS/PASEP e da COFINS, elegeu o número médio de cerca de duas incidências - poderia ter optado por três ou quatro etc. - para estabelecer presunções legais, quando, a partir de fatos conhecidos (as posteriores exportações), infere a existência de fatos prováveis, embora não comprovados (a inclusão do PIS/PASEP e da COFINS no custo dos insumos), quantificando-os pelo caminho presuntivo fixado em lei, para, em seguida, desonerar proporcionalmente as exportações. Eis que ocorre duplicidade de presunções: tanto no que tange à incidência das contribuições nas operações anteriores, quanto no que concerne ao valor do benefício. Não foi ao acaso nem à toa que o legislador denominou o incentivo de "crédito presumido". 
Ora, tratando-se, no caso, de pura presunção legal, torna-se despida de importância, no particular, a efetiva realidade. A fórmula de cálculo estabelecida pelo legislador é plena e absolutamente fechada e inflexível. Assim, se o exportador comprovar, de um lado, que existiram mais do que duas incidências dessas contribuições quanto aos seus insumos, antes da respectiva aquisição, nem por isso poderá elevar o percentual fixado para o cálculo do incentivo. De outro lado, a comprovação da nãoincidência dessas contribuições na última operação de aquisição dos insumos, como ocorre, por exemplo, no caso de serem pessoas físicas ou cooperativas os fornecedores, ou a comprovação da não-incidência nas duas últimas operações, igualmente não reduz nem afasta o incentivo. Tudo porque se trata, nos precisos termos da lei concessiva, de inegável presunção juris et de jure, que não admite prova em contrário. Em idêntico sentido, o pensamento de RICARDO MARIZ DE OLIVEIRA, ${ }^{16}$ bem como diversos acórdãos dos tribunais administrativos. ${ }^{17}$

Embora tenhamos atentado, no ponto de partida de nossa preocupação teleológica, para uma exposição de motivos, sem demora galgamos o plano de consideração da finalidade do incentivo (art. $1^{\circ}$ da lei em tela), em face da sua intransigente sistemática de cálculo (art. $2^{\circ}$ ), especialmente diante do percentual eleito para esse cálculo, redundando no estabelecimento de dupla presunção, quanto às incidências anteriores e quanto ao valor do benefício, tudo de modo a identificar contextualmente a vontade legal. Em suma, valendo-nos do verbo preciso de FRANCESCO FERRARA, estivemos a “... buscar não aquilo que o legislador quis, mas aquilo que na lei aparece objectivamente querido: 'a mens legis e não a mens legislatoris" $($ sic $) .{ }^{18}$ (grifamos)

\section{INTERPRETAÇÃO HISTÓRICO-EVOLUTIVA}

Quando fizemos breve menção a uma exposição de motivos, no item anterior, conquanto voltados para a finalidade legal, não deixamos de ter em vista, de certa

16 Crédito presumido ..., op. cit., p. 278-281 e 297.

17 Vejam-se, exemplificativamente, dois deles. O primeiro: "IPI - CRÉDITOS PRESUMIDOS - I) INSUMOS ADQUIRIDOS DE COOPERATIVAS E/OU MICT - Mesmo as aquisições de insumos de não contribuintes das contribuições em causa (PIS/PASEP e COFINS) dão direito ao crédito presumido, considerando-se que, em etapas anteriores, tais contribuições oneraram, em cascata, o custo do produto a ser exportado e têm sua incidência embutida nas operações anteriores (v. EM que encaminhou a MP 948/95) ..." - Ac. 202-10702, de 11.11.1998, 20 Conselho de Contribuintes, $2^{\mathrm{a}}$ Câmara, DOU 23.06.1999; e OLIVEIRA, Waldemar de. Regulamento do imposto sobre produtos industrializados anotado. 15. ed. São Paulo: Resenha, 2002, p. 194. E o segundo: "PIS E COFINS - INCENTIVO FISCAL - RESSARCIMENTO DAS CONTRIBUIÇÕES AO PIS E COFINS MEDIANTE CRÉDITO PRESUMIDO DE IPI ... - AQUISIÇÕES DE NÃO CONTRIBUINTES - ... A forma de cálculo prevista na norma legal estabelece uma ficção legal, aplicável a todas as situações, independentemente da efetiva incidência das contribuições na aquisição das mercadorias ou nas operações anteriores ..." Ac. 202-06484, de 11.04.2000, $2^{\circ}$ Conselho de Contribuintes, DOU 28.09.2001; e OLIVEIRA, Waldemar de. Regulamento ..., op. cit., p. 196-197.

18 Interpretação ..., op. cit., p. 135. 
forma, a occasio legis. Não se trata disso, agora, muito menos de cogitar dos trabalhos parlamentares preparatórios. A indagação excede o apenas histórico, invadindo a seara do histórico-evolutivo, para acompanhar, no que for relevante, o evolver histórico da intentio legis.

Foi pioneiro, no particular, RICARDO MARIZ DE OLIVEIRA, debruçando-se sobre a Medida Provisória ${ }^{0} 725$, de 24.11.1994. ${ }^{19}$ Seguiremos seu exemplo, não obstante preferirmos o exame da Medida Provisória $n^{\circ}$ 674, de 25.10.1994, que, antes daquela, instituiu um benefício que se aproximava do crédito presumido, então denominado de "crédito fiscal", resultando da aplicação do "... percentual de $2,65 \%$..." (art. $3^{\circ}$ ), e era “... condicionado à apresentação, pelo exportador, das guias correspondentes ao recolhimento, pelo seu fornecedor imediato, das contribuições devidas ..." (art. $5^{\circ}$ ). Sistemática essa que permaneceu até a Medida Provisória n ${ }^{\circ}$ 905, de 21.02.1995.

Aqui sim estávamos, à época, diante do ressarcimento das contribuições incidentes na específica operação de aquisição, diante de um crédito fiscal, não presumido, como demonstra a necessidade de comprovação do recolhimento correspondente. Entretanto, sabemos que o legislador modificou a sistemática, a partir da Medida Provisória ${ }^{\circ}$ 948, de 23.03.1995, mantendo-a então até a Medida Provisória $\mathrm{n}^{\circ}$ 1.484-27, de 22.11.1996, a última da série, e inclusive na sua conversão na Lei $\mathrm{n}^{\circ}$ 9.363/96, pela consideração da cumulatividade dessas contribuições, da presunção de incidência nas etapas anteriores de comercialização e de um novo percentual para o cálculo presumido do incentivo (5,37\%). E modificou certamente por ter compreendido que o crédito fiscal, apurado pelo percentual de $2,65 \%$, não era o bastante para fazer frente à multiplicidade de incidências cumulativas das contribuições em questão.

Sabemos que a edição de uma lei nova tem o condão de facilitar, pelo contraste com a anterior, tanto o entendimento da lei substituidora, quanto o da lei substituída. E é evidente que não se pode hoje insistir na manutenção da exegese anterior, em face da alteração de toda a sistemática (elevação do percentual, eliminação da exigência de comprovação do recolhimento, instituição das presunções legais etc.).

Especificamente, a anterior determinação de que o produtor-exportador comprovasse o recolhimento das contribuições por parte do fornecedor dos insumos, como condição para o gozo do benefício, foi objeto de revogação tácita pela nova sistemática. E não se pode tolerar, é claro, que o intérprete venha a ressuscitá-la, por mera atividade hermenêutica, hipótese em que ele estaria simplesmente se arvorando em legislador, à revelia do competente mandato popular! $!^{20}$

Eis que, uma vez mais, assiste razão a CARLOS MAXIMILIANO: “... pelo espírito das alterações e reformas sofridas por um preceito em sua trajetória histórica, chega-se ao conhecimento do papel que ele é chamado a exercer na atualidade". ${ }^{21}$

19 Crédito presumido ..., op. cit., p. 285-296 e 298.

20 Assim também RICARDO MARIZ DE OLIVEIRA, Crédito presumido ..., op. cit., p. 277, 285-296 e 298.

21 Hermenêutica ..., op. cit., p. 140. 


\section{INTERPRETAÇÃO LITERAL}

É incontroverso que a literalidade, gramaticalidade ou filologia do texto não encontra lugar sozinha como método interpretativo; justificando-se tão-somente como elemento adicional e complementar do processo hermenêutico.

É nessa condição que a ela recorremos no tema sob análise.

Trata-se da reflexão acerca da base de cálculo do crédito presumido, conforme o disposto no art. $2^{\circ}$ da referida lei, a saber: "A base de cálculo do crédito presumido será determinada mediante a aplicação, sobre o valor total das aquisições de matériasprimas, produtos intermediários e material de embalagem referidos no artigo anterior, do percentual correspondente à relação entre a receita de exportação e a receita operacional bruta do produtor exportador" (grifamos).

Neste passo, são preciosas as considerações de SERAFIM FERNANDES CORRÊA, respeitado conselheiro, ao relatar numerosas decisões administrativas, das quais selecionamos, a título meramente exemplificativo, parte da ementa de uma delas: ${ }^{22}$

“... CRÉDITO PRESUMIDO DE IPI NA EXPORTAÇÃO-A base de cálculo do crédito presumido será determinada mediante a aplicação, sobre o valor total das aquisições de matérias-primas, produtos intermediários e material de embalagem referidos no art. $1^{\circ}$ da Lei $n^{\circ} 9.363$, de 13.12.1996, do percentual correspondente à relação entre a receita de exportação e a receita operacional bruta do produtor exportador ( $\operatorname{art.} 2^{\circ}$, da Lei $\mathrm{n}^{\circ}$ 9.363/96). A lei citada refere-se a 'valor total' e não prevê qualquer exclusão. As Instruções Normativas SRF n ${ }^{\circ} \mathrm{s}$ 23/97 e 103/97 inovaram o texto da Lei $n^{\circ} 9.363$, de 13.12.1996 ... Tais exclusões somente poderiam ser feitas mediante lei ... visto que as instruções normativas são normas complementares das leis (art. 100 do CTN) e não podem transpor, inovar ou modificar o texto da norma que complementam ..."

Já se tentou defrontar a lógica desse raciocínio, que entendemos irretocável, mediante a alegação de que "... o valor total das aquisições ..." mencionadas no dispositivo são as referidas no artigo anterior, isto é, que tenham sofrido a incidência das contribuições do PIS/PASEP e da COFINS, esquecendo-se os argumentos atrás já arrolados. Trata-se de mera desatenção, que a própria gramática do texto esclarece plenamente: “... o valor total das aquisições de matérias-primas, produtos intermediários e material de embalagem referidos no artigo anterior ..." (grifamos). Eis que a referência ao artigo anterior não diz respeito às aquisições ali mencionadas, pois, para isso, o verbo deveria ter sido conjugado no feminino plural (aquisições ... referidas no artigo anterior), quando o foi no masculino plural (matérias-primas, produtos intermediários e material de embalagem referidos no artigo anterior), dizendo portanto respeito aos insumos adquiridos no mercado interno para utilização no processo produtivo. Vejase, em idêntico sentido, RICARDO MARIZ DE OLIVEIRA. ${ }^{23}$

22 Acórdão n ${ }^{\circ}$ 201-72.755, de 18.05.1999, $2^{\circ}$ Conselho de Contribuintes, $1^{\text {a }}$ Câmara, DOU 16.11.1999; e OLIVEIRA, Waldemar de. Regulamento do imposto sobre produtos industrializados anotado. 15. ed. São Paulo: Resenha, 2002, p. 194-195.

23 Crédito presumido ..., op. cit., p. 281-282. 


\section{NÃO INTERPRETAÇÃO LIBERAL, MAS SISTEMÁTICA}

A interpretação que estamos aqui a defender, que admite o valor total das aquisições de insumos na determinação da base de cálculo do incentivo, inclusive em face da não-incidência das contribuições do PIS/PASEP e da COFINS na última operação, já foi classificada como “... uma interpretação liberal, não permitida ... nas hipóteses de renúncia fiscal”, que demandaria interpretação restritiva, na apreciação do conselheiro JORGE FREIRE, em declaração de voto já antes citada. ${ }^{24}$ Conquanto reconhecendo interessante o juízo formulado, dele discordamos, nos termos abaixo.

Tem o intérprete certamente em mira o disposto no art. 111 do Código Tributário Nacional, Lei ${ }^{\circ}$ 5.172, de 25.10.1966, segundo o qual "interpreta-se literalmente a legislação tributária que disponha sobre ..." suspensão da exigibilidade ou exclusão do crédito tributário, inclusive isenções, bem como sobre dispensa de "obrigações acessórias".

Não paira dúvida na doutrina acerca de ter sido esse um momento particularmente infeliz do legislador do CTN. PAULO DE BARROS CARVALHO, a respeito, trata do “... desprestígio da chamada interpretação literal ...", acrescentando que "... o texto escrito ... não pode ser mais que a porta de entrada para ... vontade da lei". ${ }^{25}$ CARLOS MAXIMILIANO afirma que essa forma de interpretação, "como toda meia ciência, deslumbra, encanta e atrai; porém fica longe da verdade ...". ${ }^{26}$ Feroz, no entanto, é a crítica de JOSÉ SOUTO MAIOR BORGES, que principia por lembrar que, para LUIS RECASÉNS SICHES, o grande teórico geral do direito mexicano, a determinação legislativa da interpretação literal consiste em "... um enorme disparate ..."; identifica tal dispositivo do Código como “... um retrocesso e um injustificado preconceito ...", pois "determinar a interpretação literal é praticamente mutilar a interpretação, ou mesmo suprimi-la ...", uma vez que "para obedecer-se ao comando da interpretação literal, há que desobedecer-se muitas vezes a mens legis". ${ }^{27}$ Por isso, assevera SOUTO MAIOR que "esta subordinação acrítica e servil do intérprete ao texto do referido art. 111 ... não se legitima à luz de uma análise jurídica mais severa"; e, deitando um último olhar ao dispositivo, conclui que nele "não está dito porém que a isenção 'só', 'exclusivamente', 'unicamente' etc. submete-se a interpretação literal. O advérbio ... excluiria outros métodos de interpretação. Essa prexclusão não está porém determinada pelo art. 111 ... E, a rigor, sequer poderia sê-lo" $($ sic $){ }^{28}$

Essa admissibilidade dos demais caminhos interpretativos, inclusive em relação àqueles temas arrolados no artigo em questão, constitui pensamento comum na doutrina tributária atual, que vê o dispositivo como tendente a estabelecer uma interpretação

24 Declaração de voto ..., op. cit., p. 19 e 17.

25 Curso de direito tributário. 13. ed. São Paulo: Saraiva, 2000, p. 106.

26 Hermenêutica ..., op. cit., p. 112.

27 Teoria geral da isenção tributária. 3. ed. São Paulo: Malheiros, 2001, p. 130, 127 e 131.

28 Ibidem, p. 128 e 131. 
restritiva. Por todos, à guisa de exemplo, a palavra de GILBERTO DE ULHÔA CANTO, um dos redatores do texto do CTN, que, aliás, se diz traído pela redação final desse dispositivo, quando o pretendido era, para aquelas matérias, apontar a interpretação restritiva e não extensiva. ${ }^{29}$ Melhor ainda afirmar o dispositivo como precipuamente destinado a afastar uma interpretação extensiva, na linha de julgados do Superior Tribunal de Justiça: "O real escopo do art. 111 do Código Tributário Nacional não é impor a interpretação meramente literal - a rigor impossível -, mas evitar que a interpretação extensiva ou outro qualquer princípio de hermenêutica amplie o alcance da norma" ${ }^{30}$

Contudo, em rigor, nem mesmo essa determinação legislativa de interpretação não extensiva é aplicável ao caso; nem a de uma interpretação restritiva; e muito menos a de uma interpretação literal. Ocorre que o art. 111 do Código especifica muito claramente as hipóteses de sua aplicação, quase todas elas de expressa previsão legal: suspensão da exigibilidade e exclusão do crédito tributário (arts. 97, VI; 175 e 180 do CTN), inclusive outorga de isenção ou anistia (aqui também a Constituição, art. 150, § $6^{\circ}$ ) e dispensa de "obrigações acessórias". Em nenhuma delas se enquadra a hipótese de concessão do benefício do crédito presumido, afastando assim a aplicabilidade dessa disposição interpretativa. Donde não se há de falar, no caso, em interpretação não extensiva, restritiva ou literal, tendo cabida todos os métodos interpretativos, notadamente o sistemático.

É precisamente tal método interpretativo, o sistemático, que entendemos apontar com nitidez no sentido de que, para efeito do crédito presumido instituído pela Lei $\mathrm{n}^{\circ}$ 9.363/96, como ressarcimento das contribuições do PIS/PASEP e da COFINS, incluemse entre as aquisições de insumos no mercado interno para utilização no processo produtivo, por tudo o que foi exposto, inclusive aquelas não tributadas por essas contribuições, como, por exemplo, as aquisições de pessoas físicas e de cooperativas, em que inexistiu incidência na última operação.

Outro não é o método de interpretação jurídica de que cogitamos até agora, no todo deste trabalho, senão o método sistemático. Isso porque tal opção hermenêutica compreende o método literal (item 6), no plano sintático da linguagem, bem como os métodos histórico (item 5) e teleológico (item 4), nos planos semântico e pragmático da linguagem; ou seja, a visão sistemática não só percorre todos os níveis da linguagem do direito posto, como também demanda e pressupõe todos os demais métodos interpretativos (PAULO DE BARROS CARVALHO). ${ }^{31}$

Por isso, no dizer forte de H. J. WOLFF, "a Ciência do Direito ou é sistemática ou não existe". ${ }^{32}$ Por isso, nas palavras vigorosas de JUAREZ FREITAS, “... a

29 Apud OLIVEIRA, Ricardo Mariz de. Crédito presumido ..., op. cit., p. 301-302.

30 Decisão da $1^{\text {a }}$ Turma do STJ, no Recurso Especial no 14400/SP, de 20.11.1991 - DJU 16.12.1991, p. 18507.

31 Curso ..., op. cit., p. 100.

32 Apud CANARIS, Claus-Wilhelm. Pensamento sistemático e conceito de sistema na ciência do direito. Trad. de A. Menezes Cordeiro. Lisboa: Gulbenkian, 1989, p. 5; El Sistema en la jurisprudencia. Trad. de Juan Antonio García Amado. Madrid: Fundación Cultural del Notariado, 1998, p. 17. 
interpretação jurídica é interpretação sistemática ou não é interpretação". ${ }^{33}$ Por isso, na expressão autorizada de JOSÉ SOUTO MAIOR BORGES, esse é o método “... característico da doutrina moderna"; ${ }^{34}$ na afirmação convicta de JUAREZ FREITAS, essa é "... a interpretação jurídica, por essência"; ${ }^{35}$ na sentença definitiva de PAULO DE BARROS, esse é "... o método por excelência". ${ }^{36}$

\section{NÃO AS INSTRUÇÕES NORMATIVAS, MAS A LEI}

Carecem, portanto, de embasamento legal as instruções normativas SRF que restringem as possibilidades de crédito presumido pelas quais acima concluímos $\left(\mathrm{n}^{\circ} \mathrm{s}\right.$ 23/97 e 103/97), bem como igualmente carece do mesmo fundamento a orientação administrativa que as confirma. E muito embora esses atos administrativos normativos, como normas complementares que são, integrem a legislação tributária (CTN, arts. 96 e 100, I), cremos inadequada a assertiva atrás da qual freqüentemente se oculta a autoridade administrativa julgadora, alegando que não lhe cabe questioná-las, pelo dever de agir vinculadamente à legislação tributária. Se a atividade administrativa de lançamento e cobrança do tributo é inegavelmente vinculada (CTN, arts. $3^{\circ}$ e 142 , parágrafo único), enfatize-se que tal vinculação é em primeiríssimo e irrecusável lugar à lei em sentido estrito, e apenas secundariamente ao restante da legislação tributária hierarquicamente inferior, de modo que, antes de se atentar para as referidas instruções normativas, é de todo necessário prestar reverência ao disposto na Lei nº 9.363/96.

\section{CONCLUSÃO: MATO OU MORRO}

Aqueles que professam o entendimento segundo o qual se recusa a inclusão de insumos não tributados pelo PIS/PASEP e pela COFINS na base de cálculo do crédito presumido do IPI estão, de fato, abraçando uma interpretação literal. Essa forma de interpretação, informa-nos LUIZ FERNANDO COELHO, “... teve o seu apogeu na escola de Bolonha, no século XI ...", ${ }^{37}$ e se vivemos hoje o século XXI, já lá se vai quase um milênio! "Só os ignaros poderiam ainda orientar-se ..." por tão arcaico método (CARLOS MAXIMILIANO)! ${ }^{8}$ Trata-se de uma "... leitura de leigos ...", adverte GERALDO ATALIBA! ${ }^{39}$ Por isso típica de quem “... é simples pragmático ...” e “... não merece o nome de jurisconsulto ..." (VICO) $!^{40}$ Afinal, desde o Direito Romano, já ensinava CELSO, no Digesto, que “... é contra Direito julgar ou emitir parecer, tendo diante dos olhos, ao invés da lei em conjunto, só uma parte da mesma"!41

33 A interpretação sistemática do direito. São Paulo: Malheiros, 1995, p. 175.

34 O contraditório no processo judicial (uma visão dialética). São Paulo: Malheiros, 1996, p. 15.

35 A interpretação ..., op. cit., p. 188.

36 Curso ..., op. cit., p. 100.

37 Lógica jurídica e interpretação das leis. Rio de Janeiro: Forense, 1981, p. 208.

38 Hermenêutica ..., op. cit., p. 122.

39 Apud OLIVEIRA, Ricardo Mariz de. Crédito presumido ..., op. cit., p. 299.

40 Apud MAXIMILIANO, Carlos. Hermenêutica ..., op. cit., p. 112.

41 Apud idem, ibidem, p. 129. No original latino: "Incivile est, nisi tota lege perspecta, una aliqua particula ejus proposita, judicare, vel respondere". 
Já aqueles que preconizam a visão de conformidade com a qual se defende a inclusão de insumos não tributados pelo PIS/PASEP e pela COFINS na base de cálculo do crédito presumido do IPI estão, em verdade, esposando uma hermenêutica sistemática. Para esses, "em regra, só do complexo de palavras empregadas se deduz a verdadeira acepção de cada uma, bem como a idéia inserta no dispositivo" (BERNHARD WINDSCHEID),"42 "A verdade inteira resulta do contexto, e não de uma parte truncada, quiçá defeituosa, mal redigida; examine-se a norma na íntegra, e mais ainda: o Direito todo, referente ao assunto" (CARLOS MAXIMILIANO). ${ }^{43}$ Embora, como os outros, eles também partam da literalidade do texto, atingem muito mais além, mergulhando na sistematicidade do contexto, uma vez conscientes de que "a primeira exigência do intérprete permanece sempre: determinar o sentido literal e afirmá-lo com todo o peso que ele possui. Depois de afirmado o sentido literal, buscar 'por trás das palavras' e descobrir o sentido que isso tem para nós" (CARLOS MESTERS). ${ }^{44}$

Os partidários da literalidade são como o turista de que falávamos no princípio, que, ao "Mato ou Morro!" do líder revolucionário, reagem com arrebatamento e irreflexão, atirando-se à admiração gratuita da "coragem e ousadia" do líder e do povo, por sua açodadamente presumida "dedicação aos ideais revolucionários"! Haverão de prestar contas ao ciumento deus da linguagem, porque, irreverentes e desmazelados, tomaram suas palavras em vão! E serão inevitavelmente lançados na confusão e na obscuridade!

Os cultores da sistematicidade são como o turista ideal de que cogitávamos, que chegou antes ou permaneceu depois, e, ao "Mato ou Morro!” do líder revolucionário, reagem com prudência e sensatez, avaliando cautelosamente o ambiente e logo percebendo o declínio do movimento revolucionário e a sua fatal derrocada. Nada têm a temer do enciumado deus da linguagem, porque, reverentes e ponderados, não tomaram suas palavras em vão. Estes infalivelmente permanecerão na luminosidade e no discernimento!

E aí está a Lei ${ }^{\circ}$ 9.363/96 a desafiar-nos, entre outras questões, com os insumos não tributados pelo PIS/PASEP e pela COFINS em face do direito ao crédito presumido do IPI! Aí está o líder revolucionário a dirigir-nos o equívoco "Mato ou Morro!". O que faremos? Como apologistas do entendimento literal, buscaremos líder e povo nos campos de batalha, esperando surpreendê-los na prática de grandiosos atos de heroísmo cívico? Ou, como prosélitos da exegese sistemática, diligenciaremos por localizá-los em desabalada e irrefreável fuga, pelos matos e morros da vida? Aí está o zeloso deus da linguagem, prestes a julgar-nos pelo uso e pela interpretação de suas palavras ... "... é chegada a hora do seu juízo"! (Ap. 14,7). 